\title{
The airport atmospheric environment: respiratory health at work
}

\author{
Léa Touri*, Hélène Marchetti*, Irène Sari-Minodier*,\#, , \\ Nicolas Molinari ${ }^{+}$and Pascal Chanez ${ }^{\S, f}$
}

\begin{abstract}
Air traffic is increasing, raising concern about local pollution and its adverse health effects on the people living in the vicinity of large airports. However, the highest risk is probably occupational exposure due to proximity. Jet exhaust is one of the main concerns at an airport and may have a health impact, particularly on the respiratory tract. Current studies are neither numerous enough nor strong enough to prove this kind of association. Yet, more and more people work in airports, and occupational exposure to jet exhaust is a fact. The aim of this review was to evaluate the existing knowledge regarding the impact of airport pollution on respiratory health. We conducted systematic literature searches to examine workplace exposures.
\end{abstract}

\section{KEYWORDS: Airport, air traffic, jet exhaust, occupational exposure, respiratory problems, respiratory} tract

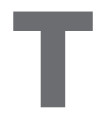
he International Air Transport Association announced a slight decline in air traffic in May 2012 due to the economic environment, but air flight transport should continue to grow in the future as there is a trend to optimise time over shorter distances. Major hub airports are not big enough and are in need of a geographic expansion, which is often discussed.

These changes cannot be made without taking into account the "expansion" of the adverse effects, both for workers who operate in the airport and for the surrounding neighbourhood. It is not sufficient only to discuss a landscape change or the risk of accident. Air pollution is a major concern for people situated at or near airports. These issues necessitate additional studies. The larger the airport, the stronger the impact on the population's health is [1]. Therefore, in this review, we discuss whether there is a correlation between atmospheric exposure at the airport, and exposure in the vicinity and occupational exposure (fig. 1).

\section{AIRPORT ATMOSPHERIC ENVIRONMENT}

Different research teams have focused on the characterisation of air pollution in the airport area and its surroundings. The concentration of particulate pollutants seems to be inversely proportional to the distance from the airport: the further away you are from the airport platform, the lower the pollution is [2]. Kerosene is the major compound in jet fuel and has a specific odour, especially before fuel combustion, which can be smelled $>8 \mathrm{~km}$ from the airport [3].

The main polluting substances considered in this environment are nitrogen oxides, carbon dioxide, carbon monoxide, volatile organic compounds (VOCs) including polycyclic aromatic hydrocarbons (PAHs), sulfur dioxide [4], and fine and ultrafine particles (UFPs) [5].

PAHs are dangerous. They have been measured and characterised for decades. Thus, it has been established that aromatic hydrocarbons are a significant part of jet exhaust pollution [2, 6]. Different types of volatile PAHs were identified using a sampler placed outside in a residential area very close to an airport. It is interesting to note that the concentration of the particulate phase measured near homes was similar to that at the end of runways [7].

It has been suggested that aviation can cause largescale increases $(>30 \%)$ of black carbon particles in the upper troposphere and lowermost stratosphere of regions highly frequented by aircraft [8]. These particles are then disseminated in the atmosphere. UFPs represented $15-18 \%$ of the particulate concentration in an airport flight path atmosphere (Taiwan International Airport, Taipei, Taiwan) [9] and this rate varied depending on the engine, the type of fuel and climate conditions [10].

Some studies outline that soot particles could have adverse health effects, especially on the

\section{AFFILIATIONS}

*Aix-Marseille Université, Faculté de médecine de la Timone, Service de santé au travail, Marseille, \#Aix-Marseille Université, UMR CNRS 7263 IMBE, Marseille, "FR CNRS 3098 ECCOREV, Europôle de l'Arbois, Aix-en-Provence, and +Service DIM, UMR 729 mistea Hopital La Colombière, CHRU

Montpellier, Montpellier,

${ }^{\S}$ Département des maladies respiratoires, Assistance Publique Hôpitaux de Marseille, Marseille, and fLaboratoire d'immunologie INSERM CNRS U 1067, UMR7733, AixMarseille Université, Marseille, France.

CORRESPONDENCE

$P$. Chanez

Département des maladies respiratoires

AP-HM

CNRS U 600

UMR6212

Boulevard de Sainte Marguerite

Marseille 13008

France

E-mail: Pascal.chanez@

univ-med.fr

Received:

Sept 212012

Accepted after revision:

Oct 072012

PROVENANCE

Submitted article, peer reviewed. 


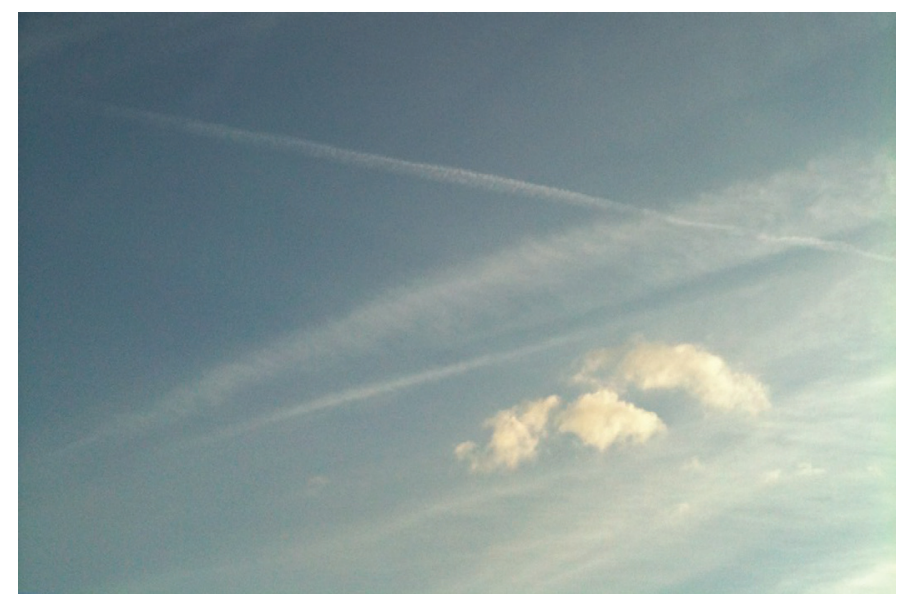

FIGURE 1. Jet exhausts in the sky.

respiratory tract, because of their tiny size [11]. Experimental studies have demonstrated that the elementary particle size in airports or close to aircrafts was between 23 and $36 \mathrm{~nm}[12,13]$. Recently, around Los Angeles International Airport (LAX; Los Angeles, CA, USA), aircraft UFP emissions with a median size of $\sim 11 \mathrm{~nm}$ were observed [14]. This is consistent with the observation at LAX that there was a bimodal distribution of particle size showing peaks at $\sim 12$ and $80-90 \mathrm{~nm}$ diameter [15].

An analysis of atmospheric health impacted around $\mathrm{O}^{\prime}$ Hare International Airport (Chicago, IL, USA) indicated that the concentrations of the aforementioned pollutants, although high, especially downwind, were similar to those from road traffic emissions in urbanised areas [16].

It is therefore difficult to focus specifically on air traffic pollution because the rates of pollutants are the same as those found in highly urbanised areas [17].

\section{AIRPORT VICINITY}

In fact, several studies, especially in Europe and North America, have been conducted since the 1990s to assess the health impact on people living close to airports, as well as air traffic risks such as noise and air pollution. However, there is a lack of data regarding relationships between airport atmospheric pollutants and respiratory disorders.

In the Netherlands, the health authorities are interested in the topic, and many studies have been conducted at the Schiphol hub airport (Amsterdam, the Netherlands) and in its vicinity. It has been determined that people living near Schiphol complained about respiratory problems [18] comprising coughing, an increase in the perception of shortness of breath and wheezing onset associated with a decreased lung function. An increase in the intermittent use of bronchodilators was noted for people previously suffering from chronic respiratory diseases; they decompensated more often [4]. These functional signs were most frequently identified near the hub and decreased with the distance from the airport [18]. This notion confirmed results of a study conducted in the USA. A significantly larger number of hospitalisations due to acute respiratory symptoms was highlighted for people living within $8 \mathrm{~km}$ of major airports like LaGuardia Airport (New York, NY, USA) or Greater Rochester International Airport (Rochester,
NY) compared with those living beyond $8 \mathrm{~km} \mathrm{[19].} \mathrm{The}$ intensity of respiratory symptoms evolved according to the concentration of air pollution.

The Dutch Working Group focused on the issue of airport respiratory health impact on vicinity and concluded that currently there was no direct association between airport air pollution and other respiratory problems other than those encountered in areas of high urban pollution [4].

The various studies are very descriptive and include many confounding factors, so we cannot compare or draw conclusions with certainty. To further support the hypothesis of an impact on respiratory functions directly related to airportspecific air pollution, work should be carried out with the target populations that are most at risk, such as employees who work in hub airports.

\section{AIRPORT WORKERS: THE POPULATION MOST EXPOSED}

In 1999, the effect of occupational exposure to aircraft fuel and jet exhaust on pulmonary function and respiratory symptoms in Birmingham International Airport (Birmingham, UK) workers was reported. This work suggested that there was a link between high occupational exposure to aviation fuel or jet exhaust and excess respiratory tract symptoms, consistent with the presence of a respiratory irritant. It was a cross-sectional survey using a questionnaire filled out by the participants themselves. Respiratory and immunological function assessments and an exhaled carbon monoxide measurement were conducted with male full-time airport workers classified into three groups according to their exposure level [20].

Although neither spirometry nor skin tests demonstrated a difference between groups, it appeared that high exposure is significantly associated with a runny nose and a cough with phlegm. The odds ratios were 2.9 and 3.5, respectively $(\mathrm{p}<0.05)$, after adjustment for age, smoking and seasonal rhinitis. Furthermore, no obvious link was demonstrated between the presence of shortness of breath or wheeze and high exposure (table 1). Exhaled carbon monoxide, adjusted for smoking, was similar for all groups. However, these results need to be confirmed by further studies because they were limited by a lack of quantitative data on occupational exposure compared with unexposed workers and the small number of subjects involved [20].

In 2003, American researchers studied the prevalence of respiratory symptoms in flight attendants because the indoor environment in occupational settings had generated considerable concerns in the USA. An association between respiratory disorders after chronic and high exposure to aircraft air quality was suggested (long-haul rotations supported). It was stated that the aircraft cabin air supplies are first cycled through an aircraft engine. Flight attendants were asked standardised questions on respiratory health by telephone at three different international airports (Miami International Airport, Miami, FL, USA; Seattle-Tacoma International Airport, Seattle, WA, USA; and Detroit Metro Airport, Detroit, MI, USA) concerning their respiratory health. Teachers operating in the same areas constituted the control group (matched for sex and age, but with little air travel). Interviewers used a standardised questionnaire [21]. 


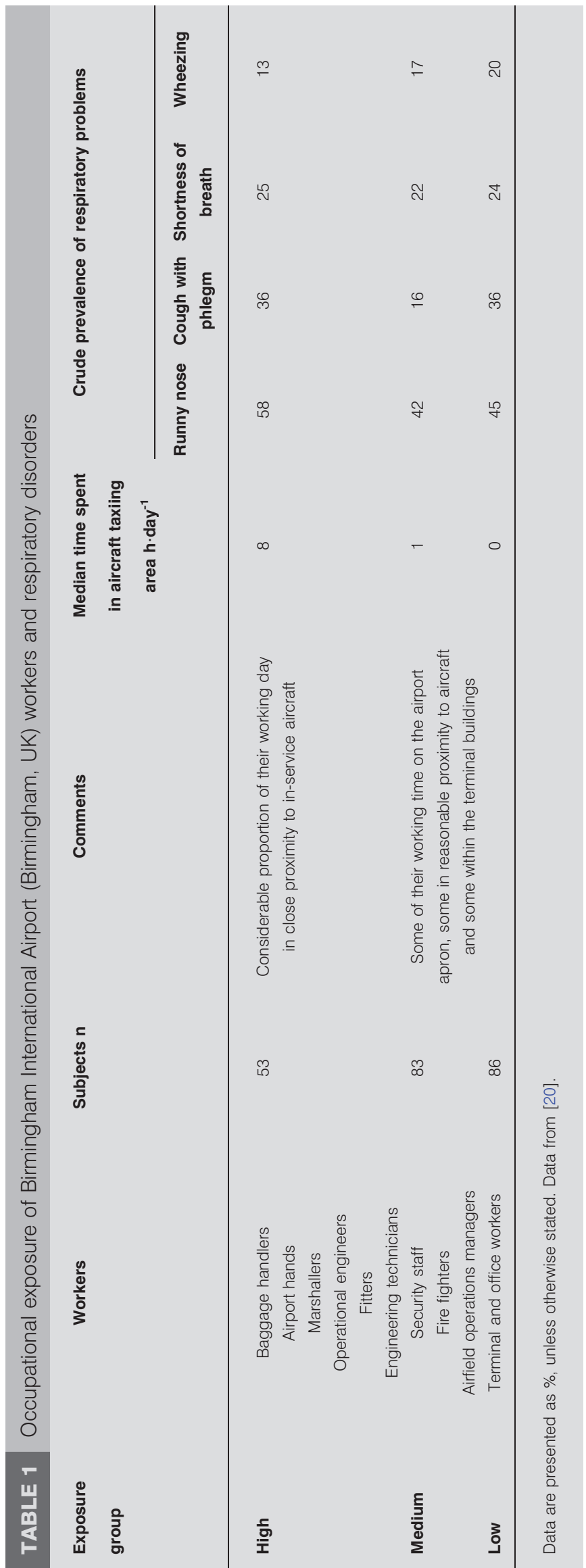

Flight attendants reported significantly more chest illnesses than teachers ( $33 \%$ and $19.3 \%$, respectively), although doctordiagnosed asthma was less common in flight attendants. The authors concluded that flight attendants had a higher respiratory disorder rate than other American female workers. The lack of asthma diagnosis might be explained by a work selection bias (inability to fly if asthma is pathology proven). The occupational origin of these symptoms was highlighted because the air cabin environment represented a unique occupational setting [21].

Pressure, humidity or many people in a small area (increased risk of infections) are specific to aircraft cabins, and the authors also outlined some contaminants that are more concentrated than in other environments: ozone, degradation products of the combustion of engine oils or hydraulic fluids. It remains difficult to go beyond hypothesis as clinical data were not associated with workplace metrology results or an objectification of medical symptoms. The link between cabin air potentially contaminated by particles of secondary emissions from jet-fuel combustion and respiratory problems could not be assessed here; there were too many missing data and too much bias [21].

In the early 2000s, a working group, appointed by the Committee on Toxicology of the US National Research Council, studied the issue of health effects of aviation fuel in the US Air Force (fig. 2). Several internal studies at the US Air Force were conducted with in the course of their work.

The working group reported the results of two studies concerning the breathing impact from Jet Propellant (JP)-8 (the main fuel used by military aviation): one by self questionnaire on respiratory symptoms of three groups of soldiers with different exposure levels; and the other based on a cohort followed by identifying the number of Air Force medical consultations for respiratory disorders compared with a control group that was not exposed. No significant difference could be demonstrated between these groups in both cases.

However, further investigations were recommended by conducting more rigorous studies taking into account the fuel in

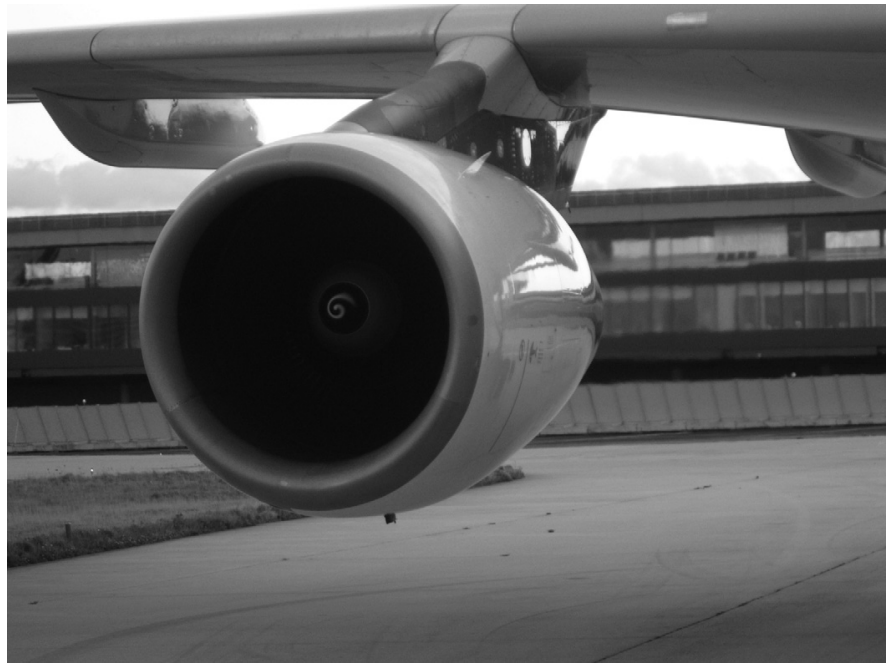

FIGURE 2. High-idling aircraft engine. 
its various states, to better characterise the workplace atmosphere and, therefore, collect clinical information and find an association with metrological data. In vitro studies on mice suggested that JP-8 aerosol is more toxic to the respiratory tract than JP-8 in vapour form [22].

To assess the potential exposure to PAHs emitted in airports, either due to the combustion of JP-8 or from other sources (road vehicles, maintenance operations, etc.), an American team attempted to characterise the ambient aerosol in various US Air Force workplaces (fig. 3).

Different kinds of measurements were used: 1) PAH concentration rendered in real-time monitoring (photoelectric aerosol sensor); and 2) low-volume air samplers for chemical analysis (gas chromatography (GC)/mass spectrometry (MS)). These monitors were used at the same time. The results were concordant on a significant increase in the concentration of PAHs in the different workplaces studied. The PAH rate was up to 25 times the content usually found in the ambient air. GC/MS clarified that PAHs were more present in a volatile phase with naphthalene and alkyl-substituted naphthalenes. Particulatephase PAHs were below the method detection limits. It is interesting to note that GC/MS revealed specific PAHs in workplaces with a major diesel exhaust particle (DEP) exposure; these compounds were not detected close to jet exhaust.

They concluded that occupational exposure to PAHs is real but it is difficult to associate a potential impact on health with this exposure. In fact, the rate measured in the break room or in the hangar, in the absence of major maintenance activities on rolling aircraft, is similar to that which was measured with the same type of monitor in the ambient air of major urban residential areas. The maximum concentration "on the tarmac" during an engine test (four reactors) was twice as large as the rate measured in a "smoking office". The emphasis was on high risk of acute exposure over short periods during certain activities (concentration peaks of PAHs) (table 2) [23].

These relatively low levels of exposure to PAHs from the combustion of aviation fuels were mainly related to the presence of naphthalene, alkyl-substituted naphthalenes and, in smaller

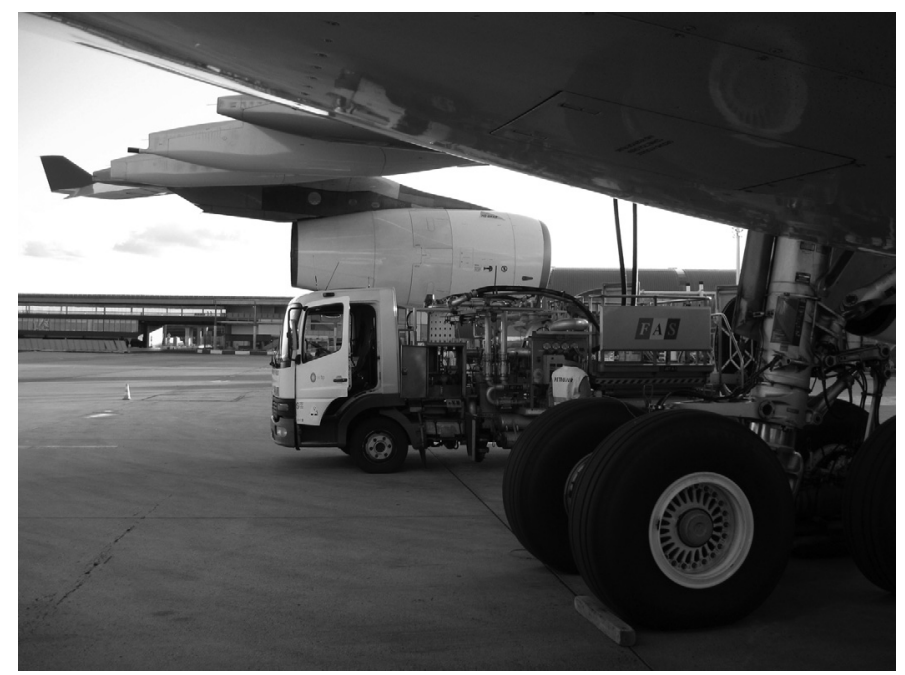

FIGURE 3. Traffic vehicles on runways. quantities, fluoranthene, pyrene and benzo[a]pyrene. Other studies confirm these data [24].

An assessment of the occupational exposure of the airport ground staff at the hub airport Charles de Gaulle (Paris, France) was carried out by occupational physicians. Atmospheric measurements were made from integrated-air samples and with individual portable tools (carbon monoxide analyser and aromatic hydrocarbons pump), specifically during the towing of the aircraft, near the towing personnel. The hydrocarbon emissions were higher under idle or low-load conditions compared with high-load conditions. It was during this activity that employees were most exposed. These results in commercial aircraft confirmed the report by CHILDERS et al. [23] that the rate of PAHs is very low, except at certain times when peaks were detected. Nitrogen oxides measured in a fixed position were below the occupational exposure limits. Carbon monoxide was below the detection limit of the device and stationary particles measured were 100 times lower than the regulatory values. The author states that all these data were conditional because the weather was not taken into account and, therefore, they only reflected the airport's ambient environment at one moment [25].

To better characterise the occupational exposure to PAHs, an Italian team decided to assess the association between atmospheric metrology (measuring levels of 23 kinds of PAHs including 16 considered most dangerous by the US Environmental Protection Agency) and a urinary $\mathrm{PAH}$ indicator (1-hydroxypyrene) in the exposed population, and to assess micronucleus and comet assays in exfoliated buccal cells. PAHs were found in greater numbers on the FiumicinoLeonardo da Vinci (Rome, Italy) apron with predominantly methylnaphthalene and acenaphthylene compared with other areas (buildings and departure terminal). The authors associated PAHs with the incomplete combustion of jet exhaust. The analysis of the rate of 1-hydroxypyrene in urine, collected at the end of the fifth day of the work week showed no significant difference between the exposed workers and the control group. Conversely, although the micronucleus test was not significant, the comet assay (confirmed by secondary analyses after culture) showed the presence of oxidative stressrelated damage to DNA. CAVALLO et al. [26] concluded that the comet assay on buccal cells was a good indicator of genotoxic and oxidative impact after chronic exposure to low doses of PAH. However, this is not clear; there are many biases in this study, with a lack of precision on the exposure time and a neglect of numerous confounding factors [26].

However, alkanes emitted by aircraft engines may be a specific aircraft emission indicator for occupationally exposed persons, as their concentration is higher than in DEPs [27], and the impact of other airport respiratory toxic products must not be neglected. Occupational physicians should consider the global exposure.

Paints may contain VOCs that are implicated in the exacerbation of pre-existing respiratory diseases such as asthma [28]. In addition, chromium found in spray paints used in the aviation industry seems to be deposited in the airway and alveolar tract [29]. Aircraft maintenance is often performed in closed, ventilated areas (hangars). These operations are very different and may require the use of paints, adhesives, oils or welding. It has been 
TABLE 2 Airport occupational exposure to polycyclic aromatic hydrocarbons (PAHs)

\begin{tabular}{|c|c|c|}
\hline Workplace & Monitor & Results \\
\hline $\begin{array}{l}\text { Background in a break room close to mainte- } \\
\text { nance hangar (no known emission sources } \\
\text { near the room) }\end{array}$ & RTM & $\begin{array}{l}0.97-40 \mathrm{ng} \cdot \mathrm{m}^{-3} \\
\text { Negligible } \\
\text { The monitors all agreed qualitatively }\end{array}$ \\
\hline $\begin{array}{l}\text { Downwind measurements during four engine } \\
\text { run-up test on flight tarmac }\end{array}$ & $\begin{array}{l}\text { RTM } \\
\text { IAS }\end{array}$ & $\begin{array}{l}\text { Maximum output of the monitor: } 4000 \mathrm{ng} \cdot \mathrm{m}^{-3} \text { (high-idle engine test) } \\
\text { PAH vapour phase dominated by naphthalene, and alkyl-substituted naphthalenes }{ }^{\#} \\
\text { PAH particulate phase }<\text { LD except benzo[a]pyrene and pyrene }\end{array}$ \\
\hline $\begin{array}{l}\text { Maintenance hangar, second step: doors opened; } \\
\text { aircraft engine exhaust was directed toward the } \\
\text { door of the maintenance hangar }\end{array}$ & RTM & $\begin{array}{l}\text { PAHs were } 10 \text { times higher than in the break room, eight times higher than those } \\
\text { recorded earlier in the maintenance hangar (first step), approximately equal to the } \\
\text { average indoor PAH concentrations in residences in a major city }\end{array}$ \\
\hline & IAS & $\begin{array}{l}\text { Vapour PAHs were two times greater than in the maintenance hangar (first step) } \\
\text { PAH particulate phase }<\text { LD }\end{array}$ \\
\hline
\end{tabular}

RTM: real time measurements; IAS: integrated air sampling associated with chemical analysis; LD: limit of detection; AGE: aerospace ground environment. ${ }^{\#}$ : present in the greatest quantities. Data from [23].

shown that this last activity is a source of not only organic UFPs but also metal UFPs such as aluminium, iron or zinc [30].

\section{DISCUSSION}

The health impact of airport occupational exposure cannot be fully considered while the risks have not been clearly identified. No study has demonstrated a significant relationship between specific exposure to jet exhaust particles and respiratory symptoms because of many confounding factors (tobacco, DEPs, etc.), insufficient sample size and a lack of quantitative data; nobody has been able to correlate jet exhaust particles with respiratory symptoms in fact. Many studies on animals and humans (in vitro and in vivo) regard nanoparticle toxicity but this research focuses on workers in nanotechnology industries who are exposed to uniquely engineered nanomaterials. Therefore, it is easier to include this kind of person in a epidemiological study with few confounding factors. However, this field of study should also include nanoparticles generated by pollution as well as manmade nanoparticles, UFPs remain a background interest despite a larger number of people being exposed. This may be because natural UFPs were considered common in the atmosphere, but with the development of industry and travel traffic, people are exposed to significant levels.

Since the air in dense urban areas does not differ from that of an airport, we must take into account atmospheric pollution in its entirety. Traffic at an airport is not only limited to aircraft runways; it also has a lot of roads for cars and cargo trucks. Furthermore, it covers a larger number of activities on a smaller geographic scale. As in urban areas, where pollution from DEPs has been proven, it is important to remember that the International Agency for Research on Cancer recently classified diesel engine exhaust as carcinogenic to humans (Group 1). This is based on sufficient evidence that exposure to DEPs is associated with an increased risk of lung cancer. The exhaust of gasoline engines is also suspected as carcinogenic (Group 2B) [31]. Therefore, toxicity due to other types of fuels must also be discussed.

Since the impact of respiratory UFPs derived from the combustion of diesel is more and more accurate, we can begin to question the existence of these particles in an airport, outdoors and indoors. We can also better characterise these particles since the majority of road vehicles use diesel, especially in France, and aeroplanes consume kerosene. A team of researchers in Marseilles has recently demonstrated in vitro that these UFPs can influence cytokine production and so impact inflammatory processes in humans [32]. For an improved approach to occupational exposure on airport aprons, the balance of each of these types of pollution should also be determined (diesel versus kerosene).

It would also be interesting to see if there is an association between ambient air metrology and objective respiratory health indicators (biometrology, functional medical exams, etc.). Depending on the impact that can be measured, key prevention and corrective methods may be considered, on a human scale (collective and individual) as well as an industrial scale.

Until a specific marker of incomplete combustion of kerosene is clearly identified, it is necessary to continue the process of 


\section{TABLE 3 Airport pollution effects on the respiratory tract in vivo}

People exposed

Respiratory symptoms
Coughing, shortness of breath, wheezing onset and decreased lung function

Exacerbation of pre-existing respiratory diseases

A runny nose and a cough with phlegm

Chest illnesses

Airport occupational exposure

Airport vicinity exposure

Exacerbation of pre-existing respiratory diseases

Chromium can be deposited in the respiratory tract
Ref.

$[18]$

[28]

[29] measuring the concentration in ambient air on the workforce, and on a larger scale, for public health. The specificity of alkanes has been discussed and should continue to be studied before being used as a marker. The difference in size between UFPs from jet exhausts and those from DEPs must be taken into consideration.

It is important to continue studies in order to characterise these pollutant substances because data gathered from other sectors attributes toxicity to the nanometric size of these particles. We know these particles have different physical and chemical properties relating to their size.

Given the enormous increase in air traffic and the controversies it has generated in recent years, airport structures are changing, not only in terms of their architecture. The use of fuel in aircrafts and road vehicles is also being redesigned (electric vehicles, organic jet fuel, etc.). There are still insufficient data and new factors must also be considered. The monitoring of the Swiss Study on Air Pollution and Lung Disease in Adults cohort reported that an improvement in air quality due to behavioural changes had a positive impact on respiratory health [33].

\section{CONCLUSION}

It is clear that airport activities are a source of air pollution. However, jet exhausts are not the only cause of this pollution. The wide range of operations on an airport base increases occupational exposures. Only a few studies have established a specific link between exposure to pollution in an airport work environment and respiratory problems (table 3). Moreover, the correlation is weak because there is a lack of power, a lack of precision over the types of jobs affected and the presence of confounding factors.

Additional studies, using more rigour and more biomonitoring in association with occupational aerosol measurements, are needed to support this hypothesis.

\section{STATEMENT OF INTEREST}

Conflict of interest information can be found alongside the online version of the article at err.ersjournals.com

\section{REFERENCES}

1 Cohen BS, Bronzaft AL. Air transportation and human health In: Nriagu JO, ed. Encyclopedia of Environmental Health. Amsterdam, Elsevier, 2011; pp. 53-63.

2 Cohen BS, Bronzaft AL, Heikkinen M, et al. Airport-related air pollution and noise. J Occup Environ Hyg 2008; 5: 119-129.
3 Franssen EAM, Staatsen BAM, Lebret E, et al. Assessing health consequences in an environmental impact assessment, the case of Amsterdam Airport Schiphol. Environ Impact As Rev 2002; 22: 633-653.

4 Health Council of the Netherlands, Committee on the Health Impact of Large Airports. Public Health Impact of Large Airports. The Hague, Health Council of the Netherlands, 1999; p. 1999/14E.

5 Nemmar A, Hoet PHM, Vanquickenborne B, et al. Passage of inhaled particles into the blood circulation in humans. Circulation 2002; 105: 411-414.

6 Spicer CW, Holdren MW, Smith DL, et al. Chemical composition of exhaust from aircraft turbine engines. J Eng Gas Turbines Power 1992; 114: 111-117.

7 Jung KH, Artigas F, Shin JY. Personal, indoor, and outdoor exposure to VOCs in the immediate vicinity of a local airport. Environ Monit Assess 2011; 173: 555-567.

8 Hendriks J, Karcher B, Dopelheuer A, et al. Simulating the global atmospheric black carbon cycle: a revisit to the contribution of aircraft emissions. Atmos Chem Phys 2004; 4: 2521-2541.

9 Lai CH, Chuang KY, Chang JW. Characteristics of nano-/ultrafine particle-bound PAHs in ambient air at an international airport. Environ Sci Pollut Res 2012 [In press DOI: 10.1007/s11356-0121083-x].

10 Kobayashi A, Kikukawa A. Increased formaldehyde in jet engine exhaust with changes to JP-8, lower temperature, and lower humidity irritates eyes and respiratory tract. Aviat Space Environ Med 2000; 71: 396-399.

11 Highwood EJ, Kinnersley RP. When smoke gets in our eyes: the multiple impacts of atmospheric black carbon on climate, air quality and health. Environ Int 2006; 32: 560-566.

12 Barone TL, Lall AA, Yifang Zhu Y, et al. Inertial deposition of nanoparticle chain aggregates: theory and comparison with impactor data for ultrafine atmospheric aerosols. J Nanopart Res 2006; 8: 669-680.

13 Smekens A, Godoi RHM, Vervoort M, et al. Characterisation of soot emitted by domestic heating, aircraft and cars using diesel or biodiesel. J Atmos Chem 2007; 56: 211-223.

$14 \mathrm{Hu} \mathrm{S}$, Fruin S, Kozawa $\mathrm{K}$, et al. Aircraft emission impact neighborhood adjacent to a general aviation airport in southern California. Environ Sci Technol 2009; 43: 8039-8045.

15 Westerdahl D, Fruin S, Fine PL, et al. The Los Angeles international airport as a source of ultrafine particles and other pollutant to nearby communities. Atmos Environ 2008; 42: 3143-3155.

16 Illinois Environmental Protection Agency Bureau of Air. Final Report: Chicago O'Hare Airport Air Toxic Monitoring Program June-December, 2000. Springfield, Illinois EPA, 2002.

17 Tesseraux I. Risk factors of jet fuel combustion products. Toxicol Lett 2004; 149: 295-300.

18 Staatsen B, Franssen E, Lebert E. Health Impact Assessment of Schiphol Airport: Executive Summary. Bilthoven, National Institute of Public Health and the Environment, 1994. 
19 Lin S, Munsie JP, Herdt-Losavio M, et al. Residential proximity to large airports and potential health impacts in New York State. Int Arch Occup Environ Healt 2008; 81: 797-804.

20 Tunnicliffe WS, O'Hickey SP, Fletcher TJ, et al. Pulmonary function and respiratory symptoms in a population of airport workers. Occup Environ Med 1999; 56: 118-123.

21 Whelan EA, Lawson CC, Grajewski B, et al. Prevalence of respiratory symptoms among female flight attendants and teachers. Occup Environ Med 2003; 60: 929-934.

22 Subcommittee on Jet-Propulsion Fuel 8, Committee on Toxicology, National Research Council. Toxicologic Assessment of JetPropulsion Fuel 8. Washington, National Academies Press, 2003.

23 Childers JW, Witherspoon CL, Smith LB, et al. Real-time and integrated measurement of potential human exposure to particlebound polycyclic aromatic hydrocarbons (PAHs) from aircraft exhaust. Environ Health Perspect 2000; 108: 853-862.

24 Iavicoli I, Chiarotti M, Bergamaschi A, et al. Determination of airborne polycyclic aromatic hydrocarbons at an airport by gas chromatography-mass spectrometry and evaluation of occupational exposure. J Chromatogr A 2007; 1150: 226-235.

25 Donne JP. Prevention of airport hazards on tarmac: 1 . Noise, 2. Chemical and particles pollution. Méd Aéronautique Spatiale 2003; 43: 6-9.
26 Cavallo D, Ursini CL, Carelli G, et al. Occupational exposure in airport personnel: characterization and evaluation of genotoxic and oxidative effects. Toxicology 2006; 223: 26-35.

27 Zeiger E, Smith L. The First International Conference on the Environmental Health and Safety of Jet Fuel. Environ Health Perspect 1998; 106: 763-764.

28 LaPuma PT, Bolch EW. The impact of recirculating industrial air on aircraft painting operations. Appl Occup Environ Hyg 1999; 14: 682-690.

29 Sabty-Daily RA, Harris PA, Hinds WC, et al. Size distribution and speciation of chromium in paint spray aerosol at an aerospace facility. Ann Occup Hyg 2005; 49: 47-59.

30 Zimmer AT, Maynard AD. Investigation of the aerosols produced by a high-speed, hand-held grinder using various substrates. Ann Occup Hyg 2002; 46: 663-672.

31 International Agency for Research on Cancer. Diesel and gasoline engine exhausts and some nitroarenes. Lyons, IARC, 2012.

32 Ferry D, Rolland C, Delhaye D, et al. Jet exhaust particles alter human dendritic cell maturation. Inflamm Res 2011; 60: 255-263.

33 Downs SH, Schindler C, Liu LJS, et al. Reduced exposure to PM10 and attenuated age-related decline in lung function. $N$ Engl J Med 2007; 357: 2338-2347. 